Published in final edited form as:

Int J Cardiol. 2005 May 25; 101(2): 173-178.

\title{
Brugada syndrome
}

\author{
Johnson Francis ${ }^{a},{ }^{*}$ and Charles Antzelevitch ${ }^{\mathrm{b}}$ \\ aMedical College Calicut, Kerala, India \\ bMasonic Medical Research Laboratory, 2150 Bleecker Street, Utica, NY 13501-1787, United \\ States
}

\section{Abstract}

The Brugada syndrome is an autosomal dominant disease with incomplete penetrance that may cause syncope and sudden cardiac death in young individuals with a normal heart. It is characterized by an electrocardiographic pattern of complete or incomplete right bundle branch block and ST segment elevation in leads V1-V3. One of the genes linked to this syndrome is SCN5A, the gene encoding for the cardiac sodium channel. Mutations in SCN5A cause a functional reduction in the availability of cardiac sodium current in Brugada syndrome. However, only 20-25\% of patients affected by this syndrome have mutations on this gene. A novel gene locus on chromosome 3, distinct from SCN5A, has been identified recently. The relative male preponderance of the phenotype, despite equal inheritance of the gene in males and females, has led to the speculation of a role for testosterone in the phenotype. The disease could manifest at first time as cardiac arrest without any previous symptom, and the electrocardiographic pattern could be intermittent, requiring a pharmacological challenge with Class I antiarrhythmic drugs to unmask ST elevation. Several conditions producing Brugada-like electrocardiographic patterns should be borne in mind and excluded while making a diagnosis of the Brugada syndrome. The management is difficult as pharmacological agents are not universally effective. The mode of treatment recommended by the majority of cardiac electrophysiologists is the implantation of a cardioverter defibrillator. Symptomatic patients with inducible ventricular arrhythmias and a positive family history should be considered for prophylactic implantation of a cardioverter defibrillator.

\section{Keywords}

Ventricular tachycardia; Ventricular fibrillation; Arrhythmia; Sudden death

\section{Introduction}

Ever since its description in 1992 by Brugada and Brugada [1], the literature on the Brugada syndrome has been growing exponentially. The syndrome is characterised by ST segment elevation in the right precordial leads and a high incidence of sudden death in individuals with structurally normal heart. The disease is recognized worldwide, although the prevalence seems much higher in some areas. Prevalence ranging from 5 to 66 per 10,000 has been reported [2].

\section{Electrocardiographic features}

Fig. 1 [3] illustrates the typical electrocardiographic (ECG) features of the Brugada syndrome as described in the 1992 article [1]. The accentuated J wave, ST segment elevation, and negative $\mathrm{T}$ wave in the precordial leads V1 to V3 are the typical features. The accentuated $\mathrm{J}$ wave

\footnotetext{
*Corresponding author. Tel. +91 495 2356888. E-mail address: pulikkottil2002@ hotmail.com (J. Francis).
} 
simulates an $\mathrm{R}^{\prime}$ and gives the appearance of right bundle branch block. The $\mathrm{R}^{\prime}$ in Brugada syndrome is thought to be due to early repolarisation of the right ventricular epicardium rather than the right bundle branch block [4]. This classical pattern has been recently designated as Type 1 [2]. A high take off ST segment elevation with upward concavity and positive or biphasic $\mathrm{T}$ wave resulting in a saddleback configuration has been designated as Type 2. Type 3 is a right precordial ST segment elevation of $<1 \mathrm{~mm}$ of saddleback-type, coved-type, or both. The ECG changes can be dynamic, with the same patient manifesting all the three types at various points of time. The arrhythmogenic substrate is believed to be due to a shift in the balance of current, which leads to the loss of the action potential dome at some epicardial sites but not at others. Loss of the action potential dome in the epicardium, but not in endocardium, leads to the development of a marked transmural dispersion of repolarization and refractoriness. Conduction of the action potential dome from sites at which it is maintained to sites at which it is lost causes local reexcitation via a phase 2 reentry mechanism. This results in a very closely coupled extrasystole, which captures the vulnerable window across the wall and triggers a circus movement reentry in the form of ventricular tachycardia or ventricular fibrillation [5]. Recurrent ventricular tachyarrhythmias attending the Brugada syndrome is often referred to as an "Electrical Storm", though this is not specific to the syndrome.

Arrhythmias and sudden death in the Brugada syndrome generally occur during sleep or at rest and are commonly associated with bradycardia as an initiating situation [6]. Although lifethreatening ventricular arrhythmias are the usual feature in the Brugada syndrome, a novel association with supraventricular tachyarrhythmias has also been described [7].

\section{Unmasking of Brugada syndrome}

The electrocardiographic manifestations of the Brugada syndrome are dynamic, and the extent of ST elevation is variable. Findings may be unmasked by potent sodium channel-blocking drugs like flecainide, ajmaline, procainamide, disopyramide, propafenone and pilsicainide [8]. A recent study showed $100 \%$ reproducibility for the flecainide challenge test. At the same time, the occurrence of major ventricular arrhythmias even in asymptomatic individuals mandate that this test be done under close medical supervision [9]. Accelerated inactivation of the sodium channel seen in the Brugada syndrome can be temperature-sensitive [10]. Several cases of fever-induced Brugada syndrome have been reported [11-13]. Some of these cases only displayed the abnormal ECG pattern, whereas others displayed both an abnormal ECG and ventricular tachyarrhythmia.

\section{Genetic defects}

A defect in the alpha subunit of the cardiac sodium channel gene SCN5A was first reported by Chen et al. [14] in 1998. Numerous SCN5A mutations have been identified since [15,16]. The syndrome has an autosomal dominant mode of inheritance with low penetrance. SCN5A mutations accounts for only 20-30\% of the Brugada cases [17]. A novel gene locus on chromosome 3, distinct from SCN5A, has been identified recently [18]. Although males and females inherit the defective gene equally, the phenotypic manifestation is 8-10 times more common in males. Two interesting cases of the normalization of the ST segment elevation following castration in patients with the Brugada syndrome have been reported recently [19]. This suggests a possible association between manifestation of the Brugada ECG pattern and testosterone, thus explaining the male preponderance.

\section{Acquired Brugada syndrome}

Acquired forms of the Brugada syndrome are gradually coming into view. Like the long QT syndrome, many cases of acquired forms of the syndrome may have a genetic predisposition. 
Among sodium channel blockers, the ability of a drug to precipitate the Brugada syndrome is related to the drug's rate of dissociation from the sodium channel [20]. Class IC antiarrhythmic agents (flecainide, pilsicainide, propafe-none) are most effective due to their slow dissociation, whereas Class IA antiarrhythmic drugs (procainamide, disopyramide, cibenzoline), which dissociate more rapidly, are less effective in elevating the ST segment and inducing VT/VF. Class IB drugs (mexiletine, lidocaine) have little or no effect due to their rapid dissociation from the sodium channel.

Psychotropic drugs, including tricyclic antidepressants (amitriptyline, nortriptyline, desipramine, clomipramine) and tetracyclic antidepressants (maprotiline), phenothiazine (perphenazine, cyamemazine), and selective serotonin reuptake inhibitors (fluoxetine), have been reported to produce a Brugada-like ST segment elevation, most likely secondary to potent $\mathrm{I}_{\mathrm{Na}}$ inhibition following overdosage [21]. A sedating, first-generation histaminic H1 receptor antagonist (dimenhydrinate; [22]) and cocaine [23] intoxication are also reported to cause the electrocardiographic sign of the Brugada syndrome.

A number of other conditions are able to induce a Brugada-like syndrome. Electrolyte abnormalities, such as hyperkalemia and hypercalcemia, have been associated with ST segment elevation in the right precordial leads. Local pressure applied to the right ventricular wall as in the case of a mediastinal tumor has also been reported to induce an ECG pattern similar to the Brugada syndrome [24]. This ECG pattern disappears after tumor removal, suggesting that it is caused by compression of the right ventricular outflow tract [24]. Another case of pericardial fluid compressing the right ventricle with Brugada-like ECG pattern was reported in a patient with rheumatoid arthritis [25]. The ECG normalized after surgery to correct the hemopericardium. Nakazato et al. [26] recently described compression of the right ventricular outflow tract by an infective mass causing a Brugada-like ST elevation, which resolved following antibiotic therapy. The ability of local pressure to give rise to an ST segment elevation has also been demonstrated experimentally in the arterially perfused right ventricular wedge preparation by Antzelevitch and Dumaine [27]. Hypothermia leads to the accentuation of Osborn or $\mathbf{J}$ waves in the inferior leads [28] and can lead to VT/VF [29]. ECG changes consistent with the Brugada syndrome has been noted during influenza virus infection [30]. The ECG pattern changed after 1 week to one of early repolarization in V1 and V2. The authors suggested an association between Brugada syndrome and viral infection.

\section{QT interval prolongation in the Brugada syndrome}

The congenital long-QT syndrome (LQT3) and the Brugada syndrome are two distinct, lifethreatening rhythm disorders linked to autosomal dominant mutations in SCN5A, the gene encoding the human cardiac $\mathrm{Na}(+)$ channel. QT-interval prolongation in the right precordial leads has been reported in the Brugada syndrome recently [31]. This observation was noted following the administration of flecainide. No change was noted in the left precordial leads.

\section{Brugada-like ECG pattern}

Several cases of ECG pattern resembling the Brugada syndrome have been reported in the literature. One of the most recent reports (in this journal) was a Brugada-type ECG with polymorphic ventricular tachycardia in a patient with isolated right ventricular infarction [32].

Sudden cardiac death with left main coronary artery occlusion in a patient whose presenting ECG suggested that the Brugada syndrome has been reported recently [33]. This patient who died suddenly during Holter ECG monitoring had a ventricular premature systole with an extremely short coupling interval followed by torsades de pointes, soon degenerating into ventricular fibrillation. Retrospective survey of the patient's medical records revealed ECG 
findings suggesting the Brugada syndrome. Complete thrombotic occlusion of the left main coronary artery was seen at the autopsy.

Electrocardiographic pattern suggestive of the Brugada syndrome has also been reported in individuals with pectus excavatum [34]. It was hypothesised that the chronic injury to the right ventricle by the thoracic deformity was causative.

Patients with arrhythmogenic right ventricular cardiomyopathy (ARVC) may also display electrocardiographic features of the Brugada syndrome. Some workers have suggested that this phenotype is an early manifestation of the ARVC. But these two disorders are genetically distinct entities [8].

\section{Exercise testing}

The response to exercise of the ST elevation in the Brugada syndrome is variable. ST elevation normalising during exercise [35,36], as well as worsening with exercise, has been described [37,38]. Samniah et al. [39] made another interesting observation in a patient with a history of recurrent postexertion lightheadedness and near syncopal spells in the setting of a family history of unexplained sudden cardiac death. ECG and pharmacological stress test findings were suggestive of the Brugada syndrome. Exercise stress test reproduced the patient's usual symptoms during the recovery period and was consistent with a typical vasovagal faint. The patient was treated with midodrine and remained symptom-free during the 16-month followup period.

Strenuous exercise may increase body core temperature sufficient to unmask the Brugada syndrome in some patients, although no demonstration of this has been reported.

\section{Heart rate variability}

Hermida et al. [40] found that decreased nocturnal standard deviation of averaged normalnormal intervals (SDANN) was an independent marker to identify patients at risk of arrhythmic events in the Brugada syndrome. Krittayaphong et al. [41] noted low heart rate variability at night, which may predispose to the occurrence of ventricular fibrillation. Spectral analysis of the heart rate variability has demonstrated increased sympathetic activity followed by attacks of ventricular fibrillation [42].

\section{Determinants of sudden cardiac death}

It is generally agreed that patients with the Brugada syndrome who were resuscitated from an episode of ventricular fibrillation are at high risk for recurrence. The prognosis and therapeutic approach in patients with a diagnostic ECG but without a previous history of sudden cardiac death is controversial. The inducibility of a sustained ventricular arrhythmia on programmed stimulation $(P<0.0001)$ and a history of syncope $(P<0.01)$ have been noted as predictors of events in a large study of this subset, which was recently published by the Brugada et al. [43]. In this study of 547 patients, 128 had suffered from at least one episode of syncope. During programmed ventricular stimulation, a sustained ventricular arrhythmia was induced in 163 of 408 patients. During a mean follow-up of 24+/-32 months, 45 patients (8\%) suffered sudden death or documented ventricular fibrillation. They found a $27.2 \%$ probability of an event by logistic regression analysis in a patient with a spontaneously abnormal ECG, a previous history of syncope, and inducible sustained ventricular arrhythmias. Hence, inducibility of ventricular arrhythmias and a previous history of syncope are markers of a poor prognosis in the Brugada syndrome. Symptomatic patients require protective treatment even when they are not inducible. Asymptomatic patients can be reassured if they are noninducible. 


\section{Therapeutic options}

Although implantation of an implantable cardioverter defibrillator (ICD) is viewed universally as the "gold standard" therapy for patients with recurrent ventricular fibrillation, various therapeutic options have been tried in the Brugada syndrome for the prevention of sudden cardiac death. Tsuchiya [44] has detailed the role of pharmacological therapy in a recent review article. Belhassen et al. [45] used electrophysiologic-guided therapy with orally administered Class IA agents (mainly quinidine) with good results. Similar results were reported by Suzuki et al. [46]. Yan and Antzelevitch [5], in their in vitro study, showed that the blockade of the transient outward current $\left(I_{\mathrm{to}}\right)$ with quinidine restored the action potential dome, normalized the ST segment, and prevented ventricular tachycardia/fibrillation.

Tedisamil and isoproterenol have been shown to normalize the ST elevation in the Brugada syndrome [47,48]. Phosphodiesterase III inhibitor cilostazol has also been reported to be useful recently [49]. But long-term efficacy in preventing sudden death is yet to be demonstrated. Implantation of a cardioverter defibrillator remains the ideal modality of treatment for the prevention of sudden death in patients at high risk. The ACC/AHA/NASPE 2002 guideline update for the implantation of cardiac pacemakers and antiarrhythmia devices has included Class IIb indication for ICD implantation in patients with the Brugada syndrome and syncope or family history of sudden cardiac death [50]. The Task Force on Sudden Cardiac Death of the European Society of Cardiology has recommended ICD implantation in survivors of cardiac arrest (Class I). Prophylactic use of ICD in patients with syncope/VT has been designated Class I and the use in asymptomatic patients inducible with programmed electrical stimulation as Class IIb [51]. Supportive pharmacological therapy may have a role in reducing the number of defibrillator discharges, thereby increasing the longevity of the device. An excellent editorial published by Belhassen et al. [52] has discussed the relative importance of ICD and pharmacological therapy. They call upon investigators to reconfirm the results of pharmacotherapy via randomised control trials designed to compare the different modalities of the treatment.

\section{Limitations in knowledge of natural history}

There has been some lack of uniformity in the diagnostic criteria, and a true consensus is yet to be arrived at. Therapeutic approaches have also varied, and the follow-up periods have been limited. Studies with extended follow-up of 10 years or more are required before drawing conclusions on the natural history and response to therapy [15].

\section{References}

1. Brugada P, Brugada J. Right bundle branch block, persistent ST segment elevation and sudden cardiac death: a distinct clinical and electrocardiographic syndrome. J Am Coll Cardiol 1992;20:1391-6. [PubMed: 1309182]

2. Wilde AAM, Antzelevitch C, Borggrefe M, et al. Diagnostic criteria for the Brugada syndrome: a consensus report. Circulation 2002;106:2514-9. [PubMed: 12417552]

3. Brugada J, Brugada P, Brugada R. Brugada syndrome: the syndrome of right bundle branch block, ST segment elevation in V1 to V3 and sudden death. Indian Pacing Electrophysiol J 2001;1(1):6.http:// www.ipej.org/0101/brugada.htm [PubMed: 17006566]Available online ataccessed 25th December, 2003

4. Gussak I, Antzelevitch C, Bjerregaard P, Towbin JA, Chaitman BR. The Brugada syndrome: clinical, electrophysiological and genetic aspects. J Am Coll Cardiol 1999;33:5-15. [PubMed: 9935001]

5. Yan GX, Antzelevitch C. Cellular basis for the Brugada syndrome and other mechanisms of arrhythmogenesis associated with ST-segment elevation. Circulation 1999;100:1660-6. [PubMed: 10517739] 
6. Antzelevitch C, Brugada P, Brugada J, Brugada R, Towbin JA, Nademanee K. Brugada syndrome: 1992-2002: a historical perspective. J Am Coll Cardiol May 21;2003 41(10):1665-71. [PubMed: 12767644]

7. Eckardt L, Kirchhof P, Loh P, et al. Brugada syndrome and supraventricular tachyarrhythmias: a novel association? J Cardiovasc Electrophysiol Jun.;2001 12(6):680-5. [PubMed: 11405402]

8. Antzelevitch C, Brugada P, Brugada J, et al. Brugada syndrome-a decade of progress. Circ Res 2002;91:1114. [PubMed: 12480811]

9. Gasparini M, Priori SG, Mantica M, et al. Flecainide test in Brugada syndrome: a reproducible but risky tool. Pacing Clin Electrophysiol Jan.;2003 26(1 Pt 2):338-41. [PubMed: 12687841]

10. Dumaine R, Towbin JA, Brugada P, et al. Ionic mechanisms responsible for the electrocardiographic phenotype of the Brugada syndrome are temperature dependent. Circ Res 1999;85:803-9. [PubMed: 10532948]

11. Gonzalez Rebollo G, Madrid H, Carcia A, et al. Recurrent ventricular fibrillation during a febrile illness in a patient with the Brugada syndrome. Rev Esp Cardiol 2000;53:755-7. [PubMed: 10816181]

12. Saura D, Garcia-Alberola A, Carrillo P, et al. Brugada-like electrocardiographic pattern induced by fever. PACE 2002;25:856-9. [PubMed: 12049381]

13. Dinckal MH, Davutoglu V, Akdemir I, Soydinc S, Kirilmaz A, Aksoy M. Incessant monomorphic ventricular tachycardia during febrile illness in a patient with Brugada syndrome: fatal electrical storm. Europace Jul.;2003 5(3):257-61. [PubMed: 12842640]

14. Chen Q, Kirsch GE, Zhang D, Brugada R, Brugada J, Brugada P, et al. Genetic basis and molecular mechanisms for idiopathic ventricular fibrillation. Nature 1998;392:293-6. [PubMed: 9521325]

15. Priori SG, Napolitano C, Gasparini M, et al. Clinical and genetic heterogeneity of right bundle branch block and ST-segment elevation syndrome: a prospective evaluation of 52 families. Circulation 2000;102:2509-15. [PubMed: 11076825]

16. Antzelevitch C. The Brugada syndrome: ionic basis and arrhythmia mechanisms. J Cardiovasc Electrophysiol 2001;12:268-72. [PubMed: 11232628]

17. Priori SG, Napolitano C, Grillo M. Concealed arrhythmogenic syndromes: the hidden substrate of idiopathic ventricular fibrillation? Cardiovasc Res 2001;50:218-23. [PubMed: 11334825]

18. Weiss R, Barmada M, Nguyen T, et al. Clinical and molecular heterogeneity in the Brugada syndrome. A novel gene locus on chromosome 3. Circulation 2002;105:707-13. [PubMed: 11839626]

19. Matsuo K, Akahoshi M, Seto S, Yano K. Disappearance of the Brugada-type electrocardiogram after surgical castration: a role for testosterone and an explanation for the male preponderance. Pacing Clin Electrophysiol Jul.;2003 26(7 Pt 1):1551-3. [PubMed: 12914638]

20. Shimizu W, Antzelevitch C, Suyama K, et al. Effect of sodium channel blockers on ST segment, QRS duration, and corrected QT interval in patients with Brugada syndrome. J Cardiovasc Electrophysiol Dec.;2000 11(12):1320-9. [PubMed: 11196553]

21. Rouleau F, Asfar P, Boulet S, et al. Transient ST segment elevation in right precordial leads induced by psychotropic drugs: relationship to the Brugada syndrome. J Cardiovasc Electrophysiol Jan.;2001 12(1):61-65. [PubMed: 11204086]

22. Pastor A, Nunez A, Cantale C, Cosio FG. Asymptomatic Brugada syndrome case unmasked during dimenhydrinate infusion. J Cardiovasc Electrophysiol Oct.;2001 12(10):1192-4. [PubMed: 11699532]

23. Littmann L, Monroe MH, Svenson RH. Brugada-type electrocardiographic pattern induced by cocaine. Mayo Clin Proc Aug.;2000 75(8):845-9. [PubMed: 10943241]

24. Tarin N, Farre J, Rubio JM, Tunan J, Castro-Dorticos J. Brugada-like electrocardiographic pattern in a patient with a mediastinal tumor. PACE 1999;22:1264-6. [PubMed: 10461308]

25. Tomcsanyi J, Simor T, Papp L. Haemopericardium and Brugada-like ECG pattern in rheumatoid arthritis. Heart 2002;87:234. [PubMed: 11847160]

26. Nakazato Y, Ohmura T, Shimada I, Daida H. Brugada-like precordial ST elevation on ECG by anterior mediastinal infective mass lesion. Indian Pacing Electrophysiol J 2003;3(3):184.http://www.ipej.org/ 0303/nakazato2.htm [PubMed: 16943916]Available online ataccessed 5th December, 2003 
27. Antzelevitch, C.; Dumaine, R. Electrical heterogeneity in the heart: physiological, pharmacological and clinical implications. In: Page, E.; Fozzard, HA.; Solaro, RJ., editors. Handbook of Physiology. Oxford University Press; New York: 2002. p. 654-92.The Heart

28. Pilz B, Luft FC. Acquired Brugada syndrome. Am J Cardiol Sep. 15;2003 92(6):771. [PubMed: 12972135]

29. Kalla H, Yan GX, Marinchak R. Ventricular fibrillation in a patient with prominent J (Osborn) waves and ST segment elevation in the inferior electrocardiographic leads: a Brugada syndrome variant? J Cardiovasc Electrophysiol Jan.;2000 11(1):95-8. [PubMed: 10695469]

30. Kusaka K, Yamakawa J, Kawaura K, et al. Brugada-like electrocardiographic changes during influenza infection. J Int Med Res May-Jun.;2003 31(3):244-6. [PubMed: 12870380]

31. Pitzalis MV, Anaclerio M, Iacoviello M, et al. QT-interval prolongation in right precordial leads: an additional electrocardiographic hallmark of Brugada syndrome. J Am Coll Cardiol Nov. 5;2003 42 (9):1632-7. [PubMed: 14607451]

32. Hsu LF, Ding ZP, Kam R, Teo WS, Lim YL. Brugada-type ECG with polymorphic ventricular tachycardia: a red herring for isolated right ventricular infarction. Int J Cardiol Oct;2003 91(2-3): 255-7. [PubMed: 14559142]

33. Hata T, Watanabe Y, Hata Y, Fukami H, Kuroda M. Sudden cardiac death with left main coronary artery occlusion in a patient whose presenting ECG suggested Brugada syndrome. Pacing Clin Electrophysiol Nov.;2003 26(11):2175-7. [PubMed: 14622323]

34. Kataoka H. Electrocardiographic patterns of the Brugada syndrome in 2 young patients with pectus excavatum. J Electrocardiol Apr.;2002 35(2):169-71. [PubMed: 11953918]

35. Guevara-Valdivia ME, Iturralde Torres P, de Micheli A, Colin Lizalde A, Medeiros Domingo A, Gonzalez-Hermosillo JA. Electrocardiographic changes during stress test in a patient with "Brugada syndrome" [Article in Spanish]. Arch Cardiol Mex Jan.-Mar.;2001 71(1):66-72. [PubMed: 11565364]

36. Stix G, Bella PD, Carbucicchio C, Schmidinger H. Spatial and temporal heterogeneity of depolarization and repolarization may complicate implantable cardioverter defibrillator therapy in Brugada syndrome. J Cardiovasc Electrophysiol May;2000 11(5):516-21. [PubMed: 10826930]

37. Guevara-Valdivia ME, de Micheli A, Iturralde P, Colin L, Marquez MF, Gonzalez-Hermosillo JA. In process citation [Article in Spanish]. Arch Cardiol Mex Jul.-Sep.;2003 73(3):212-7. [PubMed: 14635482]

38. Furuhashi M, Uno K, Tsuchihashi K, et al. Prevalence of asymptomatic ST segment elevation in right precordial leads with right bundle branch block (Brugada-type ST shift) among the general Japanese population. Heart Aug.;2001 86(2):161-6. [PubMed: 11454832]

39. Samniah N, Iskos D, Sakaguchi S, Lurie KG, Benditt DG. Syncope in pharmacologically unmasked Brugada syndrome: indication for an implantable defibrillator or an unresolved dilemma? Europace Apr.;2001 3(2):159-63. [PubMed: 11333057]

40. Hermida JS, Leenhardt A, Cauchemez B, et al. Decreased nocturnal standard deviation of averaged NN intervals. An independent marker to identify patients at risk in the Brugada syndrome. Eur Heart J Nov.;2003 24(22):2061-9. [PubMed: 14613743]

41. Krittayaphong R, Veerakul G, Nademanee K, Kangkagate C. Heart rate variability in patients with Brugada syndrome in Thailand. Eur Heart J Oct.;2003 24(19):1771-8. [PubMed: 14522573]

42. Nakamura $M$, Isobe $M$, Imamura $H$. Incessant ventricular fibrillation attacks in a patient with Brugada syndrome. Int J Cardiol Apr. 1;1998 64(2):205-6. [PubMed: 9688440]

43. Brugada J, Brugada R, Brugada P. Determinants of sudden cardiac death in individuals with the electrocardiographic pattern of Brugada syndrome and no previous cardiac arrest. Circulation Dec. 23;2003 108(25):3092-6. [PubMed: 14623800]

44. Tsuchiya T. Role of pharmacotherapy in Brugada syndrome. Indian Pacing Electrophysiol J 2004;4 (1):26-32.http://www.ipej.org/0401/tsuchiya.htm [PubMed: 16943885]Available online ataccessed 25th December, 2003

45. Belhassen B, Viskin S, Fish R, Glick A, Setbon I, Eldar M. Effects of electrophysiologic-guided therapy with Class IA antiarrhythmic drugs on the long-term outcome of patients with idiopathic ventricular fibrillation with or without the Brugada syndrome. J Cardiovasc Electrophysiol Oct.;1999 10(10):1301-12. [PubMed: 10515552] 
46. Suzuki H, Torigoe K, Numata O, Yazaki S. Infant case with a malignant form of Brugada syndrome. J Cardiovasc Electrophysiol Nov.;2000 11(11):1277-80. [PubMed: 11083249]

47. Shimizu W, Matsuo K, Takagi M, Tanabe Y, Aiba T, Taguchi A, et al. Body surface distribution and response to drugs of ST segment elevation in Brugada syndrome: clinical implication of eighty-sevenlead body surface potential mapping and its application to twelve-lead electrocardiograms. J Cardiovasc Electrophysiol 2000;11:396-404. [PubMed: 10809492]

48. Tanaka H, Kinoshita O, Uchikawa S, Kasai H, Nakamura M, Izawa A, et al. Successful prevention of recurrent ventricular fibrillation by intravenous isoproterenol in a patient with Brugada syndrome. Pacing Clin Electrophysiol 2001;24:1293-4. [PubMed: 11523620]

49. Tsuchiya T, Ashikaga K, Honda T, Arita M. Prevention of ventricular fibrillation by cilostazol, an oral phosphodiesterase inhibitor, in a patient with Brugada syndrome. J Cardiovasc Electrophysiol 2002;13:698-701. [PubMed: 12139296]

50. Gregoratos G, Abrams J, Epstein AE, et al. ACC/AHA/NASPE 2002 guideline update for implantation of cardiac pacemakers and antiarrhythmia devices: summary article: a report of the American College of Cardiology/American Heart Association Task Force on Practice Guidelines (ACC/AHA/NASPE Committee to Update the 1998 Pacemaker Guidelines). Circulation Oct. 15;2002 106(16):2145-61. [PubMed: 12379588]

51. Priori SG, Aliot E, Blomstrom-Lundqvist C, et al. Task Force on Sudden Cardiac Death, European Society of Cardiology: summary of recommendations. Europace 2002;4:3-18. [PubMed: 11858152]

52. Belhassen B, Viskin S, Antzelevitch C. The Brugada syndrome: is an implantable cardioverter defibrillator the only therapeutic option? PACE 2002;25:1634-40. [PubMed: 12494624] 


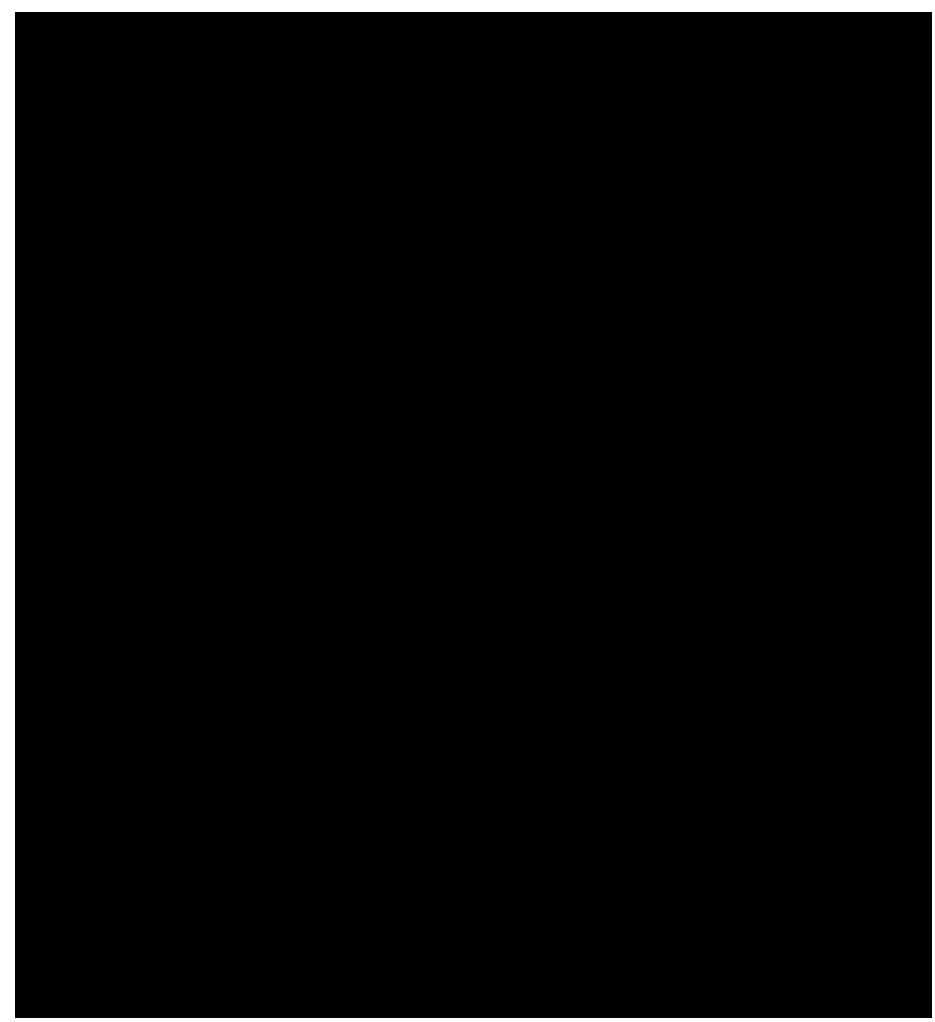

Fig. 1.

The typical electrocardiogram of a patient with the Brugada syndrome. The accentuated J wave, ST segment elevation, and negative $\mathrm{T}$ wave in the precordial leads V1 to V3 are seen (reproduced with permission from Brugada et al. [3]). 